\title{
The Impact of Inflation on Investment: The Non-Linear Nexus and Inflation Threshold in Jordan
}

\author{
Noura Abu Asab ${ }^{1}$ \& Alaaeddin Al-Tarawneh ${ }^{2}$ \\ ${ }^{1}$ School of Business, University of Jordan, P.O Box 11942, Amman, Jordan \\ Correspondence: Noura Abu Asab, School of Business, University of Jordan, P.O Box 11942, Amman, Jordan. E- \\ mail: n.abuasab@ju.edu.jo, a.alTarawneh@ju.edu.jo
}

\author{
Received: Seprember 20, 2018 \\ Accepted: October 8, 2018 \\ Online Published: November 19, 2018 \\ doi:10.5539/mas.v12n12p113 \\ URL: https://doi.org/10.5539/mas.v12n12p113
}

\begin{abstract}
This paper highlights the nonlinear relationship between inflation and investment in Jordan. Applying a threshold model over the period 1980-2016, the results reveal that investment is retracted by inflation when inflation rate reaches a threshold of $10 \%$. This suggests that inflation rates should remain below $10 \%$ to sustain and improve investment levels.
\end{abstract}

Keywords: inflation, investment. inflation threshold, threshold model

JEL Classification: O40, E31

\section{Introduction}

Inflation has long been a central and controversial issue in modern economy. Over the 1960s and 1970s, economists realized that the nexus between inflation and unemployment, suggested by the Philips curve, has neutral effects on real economic activities in the long-run (Phelps, 1968; Friedman, 1968). Therefore, monetary regimes have been redesigned to accommodate the goal of price stability as a first and foremost objective of monetary policy. However, this stability does not imply targeting a zero inflation rate, since a certain positive level (threshold) of inflation rate could stimulate the economic activity. This inflation threshold would increase consumption and investment rates and protect the economy from the drawbacks of deflation. On the other hand, if inflation exceeds the optimum threshold, investment and so economic growth will get harmed. That is why determining the inflation threshold or examining the non-linear relationship is crucial.

Monetary policy responds to inflation by raising real interest rates. This increases the marginal costs of businesses, which, consequently, decreases investment spending in most economic sectors. Lenders, represented by the financial intermediaries, for example will find that the interest rate increment just compensates the loss value of their money. And as all businesses aim to maximize profits, inflation lowers the share of profit in income for all sectors. This share of profits in income is the main factor that tends to reduce investment when inflation rises.

In fact, little is known about this relationship in developing countries, such as Jordan, where inflation is likely to be more volatile. Hence the effect of inflation on macroeconomic variables is likely to be higher. Furthermore, encouraging investment in developing countries is one main means to increase potential output and it is highly vital for the Jordan's economy. Thus this study comes to fill the gap by determining the threshold level at which inflation turns to harm investment in Jordan.

The rest of the paper is structured as follows: Section two reviews the literature. Section three provides the econometric model and the data sources. The results are illustrated in section four. Section five presents the conclusions.

\section{Literature Review}

The costs of inflation have been widely investigated. Friedman (1977) and Ball (1992) find that high inflation leads to higher inflation uncertainty. When inflation increases inflation uncertainty, the general fear about liquidity will arise and businessmen will become more concerned about how to keep operating in the market and how to avoid bankruptcy. In addition, inflation and its uncertainty lower the share of profit in income (Nevile, 1975), which depresses investment. Monetary shocks also increase the non-performing rate of businesses.

Cizkowicz (2013) believe that even low and moderate inflation is an important source of uncertainty in the 
economy. Moreover, inflation and uncertainty affect the employment of flexible factors of production. Fischer (2013) provides evidence that high inflation uncertainty decreases investment and firms under inflation uncertainty will tend to employ more working capital than fixed assets.

Inflation and inflation uncertainty impose their risk on the business environment. Among these risks are limiting the duration of investment projects, reducing the markups and hindering the decision on profitable projects (Baum et al, 2004). Chen and Boness (1975) propose an equilibrium asset pricing model under inflation uncertainty and with the assumption that the market is competitive, so market agents are price-takers. In their model, bonds and stocks are traded and agents have homogenous expectations about the probability distribution of future rate of return on risky assets and inflation rates. They find that uncertain inflation affects the cost of capital and the market price of risk, which in turn affects the firm's investment decisions. Under a simulation study carried out by Balwin and Ruback (1986), it is found that price uncertainty increases the value of shorter-lived assets which comes from the market agents' higher demand for such assets compared to the long-lived assets. Furthermore, inflation will increase the costs of information seeking, postpone spending and decisions on investment, affect the employment of flexible factors of production, and impede long-run contract investment as a result of liquidity concerns.

In fact, attracting investment relies on the ability of monetary and fiscal policy at achieving macroeconomic stability. Fulfilling this depends on the role played to reducing the potential economic risk as there are three main channels through which inflation hinders investment: the asymmetries of information channel; this includes adverse selection and moral hazards, uncertainty channel; this represents uncertainty about inflation, interest rates and exchange rates, and finally the channel of nominal rigidities in the tax system (Cizkowicz and Rzonca, 2013), (Madsen, 2003)).

Many theoretical works have been carried out to investigate the relationship between investment and inflation but little consensus has been reached on whether the nexus is positive or negative. Two theoretical backgrounds have been identified in the literature: the call option approach, where it is believed that waiting for new information in an uncertain business environment reduces investment. The other approach by Hartman (1972) and Abel (1983) reflects that increased uncertainty increases investment as the business capital is an increasing function of prices and when the variance of prices increases the expected return will also go up. Similarly, Caballero (1991), who highlights the role of market structure of industries, notes that when the market is competitive, higher prices increase investment. Nevertheless, Zeira (1990) concludes that this positive relationship may be reversed if the market agent is risk-averse, while, Huizinga (1993) argues that the effect of the nexus depends on the source of uncertainty.

Many studies, e.g. Abaidoo (2015); Iqbal and Nawaz (2009); Carruth el al (2000); Osakwe (1982), reveal that the nexus is negative. Cizkowicz (2013) for example examines the relationship between the corporate investment and inflation on a sample of 21 OECD countries over the yearly span of 1960-2005. He finds a significant and robust negative relationship and suggests that the non-linear relationship between inflation and output growth comes from the non-linearity between inflation and investment. Therefore, the central bank may exploit this negative nexus in periods of slowdown by prolonging the period of economic recovery.

Hence, although a high inflation rate can have adverse impacts on investment, there is no reason to consider that a $10 \%$ rise in inflation will produce a lower investment level and impose more risk on investment environment than the $5 \%$ (Able, 1980). That is why determining the inflation threshold or examining the non-linear relationship is crucial.

In fact, little is known about this relationship in middle-income countries, such as Jordan, where inflation is likely to be more volatile and hence the effect of inflation on macroeconomic variables is likely to be higher. In addition, Investment is highly vital for Jordan. As a small country with stable political conditions compared to other countries in its region, investment could increase capacity and productivity, strengthen fiscal position and allow the country to overcome the challenges and consequences of the political turbulence in the region. Jordan followed a private sector-led approach two decades ago and kept committed to encourage investment by applying different strategies from tax exemption to attempts to eliminate bureaucracy. However, a stable and clear monetary policy can also play a key role at maintaining and encouraging investment. This study thus comes to determine the threshold level at which inflation turns to harm investment in Jordan.

\section{Methodology Data Sources}

\subsection{Methodology}

The paper follows the methodology applied by Khan and Senhadji (2001) to examine the relationship between inflation and economic growth for a panel data study. This methodology has been widely applied by scholars to 
detect the threshold effect between variables. This is because their model construction allows continuity in the relationship that restricts small changes around the threshold level from resulting in different asymmetric effects, i.e. when inflation is increasing or decreasing. Furthermore, it avoids missing values on negative inflation rates or negative infinity values for rates close to zero by employing a hybrid function of inflation; the hybrid function is represented in equation (3).

For a specific country, the model can be represented as:

$$
\begin{gathered}
I n v_{t}=\alpha_{0}+\alpha_{1}\left(1-d_{t}^{\pi^{*}}\right)\left\{f\left(\pi_{t}\right)\right\}+\alpha_{2} d_{t}^{\pi^{*}}\left\{f\left(\pi_{t}\right)\right\}+\varepsilon_{t} \\
d_{t}^{\pi^{*}}=\left\{\begin{array}{l}
1 \text { if } \pi_{t}>\pi^{*} \\
0 \text { if } \pi_{t} \leq \pi^{*}
\end{array} \quad t=1,2, \ldots, T\right. \\
f\left(\pi_{t}\right)=\left(\pi_{t}-1\right) I\left(\pi_{t} \leq 1\right)+\log \left(\pi_{t}\right) I\left(\pi_{t}>1\right)
\end{gathered}
$$

Where $\operatorname{Inv}_{\mathrm{t}}$ is the ratio of investment to GDP at time $t, \alpha_{0}$ is the constant, $\alpha_{1}$ is the coefficient of the semi-log transformation of inflation at time $t, \alpha_{2}$ is the coefficient of extra inflation and $\pi^{*}$ is the threshold of inflation that should be estimated. The threshold level of inflation is detected at the level where $\mathrm{R}^{2}$ is maximized or the residual sum of square is minimized and when both $\alpha_{1}$ and $\alpha_{2}$ are significant. $d_{t}^{\pi^{*}}$ is a dummy variable that takes the value of 1 when inflation exceeds the threshold level of inflation, set arbitrarily from 1 to 20 , and zero when inflation rate is equal or below that threshold level.

\subsection{Data and Descriptive Statistics}

Yearly data on investment to GDP and inflation rate from 1980 to 2016 are imported from the International Monetary Fund Outlook Database. Table 1 provides descriptive statistics of both variables. Over the study span inflation rates range from around 1 to 26 .

We apply the Augmented Dickey-Fuller (ADF) test and Kwiatkowski et. al (KPSS) test to check the stationary of series; the results are presented in Table 2. For both tests, an intercept is plugged in the model specification. Both tests confirm the stationarity of the inflation rate; however, the ratio of investment to GDP is stationary according to the KPSS test only. Given this contradicting results and the drawback of ADF test, we assume that the ratio is stationary and use the robust standard error corrected for autocorrelation in the estimation process. Although the normality assumption is rejected for the dependent variable and its distribution is skewed to the right, the normality assumption of the errors of the estimated model cannot be rejected.

Table 1. Descriptive Statistics

\begin{tabular}{lll}
\hline & Inflation & Investment \\
\hline Mean & 4.75 & 26.78 \\
Median & 3.50 & 25.24 \\
Maximum & 25.66 & 46.03 \\
Minimum & -0.87 & 18.85 \\
Skewness & 2.22 & 0.89 \\
Kurtosis & 9.18 & 3.20 \\
Jarque-Bera & 92.04 & 5.16 \\
Probability & 0.00 & 0.07 \\
\hline
\end{tabular}

Note: the null hypothesis of Jarque-Bera test is that the errors are normally distributed.

Table 2. Unit Root Tests

\begin{tabular}{ccccc}
\hline Time Series & Level & Prob. & Level & Critical Value (5\%) \\
& ADF & ADF & KPSS & KPSS \\
\hline Inflation & -3.75 & 0.007 & 0.426 & 0.466 \\
Investment & -2.94 & 0.198 & 0.349 & 0.463 \\
\hline
\end{tabular}

Note: An intercept is included in the test equation and the optimal lag length is determined by the Schwarz information criterion. 


\section{Results}

This section shows the estimation of the threshold model represented in equation (1). The inflation threshold $\pi^{*}$ is determined ascendingly starting from the value one to twenty. The threshold level of inflation at which investment gets harmed by inflation is detected when the estimated parameters $\alpha_{1}$ and $\alpha_{2}$ are significant. In addition, at this level, $\mathrm{R}^{2}$ should be maximized and the sum square of residuals (RSS) should be minimized. $\alpha_{1}$ and $\alpha_{2}$ provide the total effect of inflation on investment, which is supposed to be negative. Equation 1 is estimated by Least Square Method with robust standard errors and the results are provided in Table 3.

The results suggest that when the inflation threshold is below $10 \%$, the total effect of inflation on investment is positive but insignificant. Nevertheless, the relationship between inflation and investment turns negative and significant at inflation threshold of $10 \%$. At this level, $\mathrm{R}^{2}$ reaches the highest value, i.e. the RSS is minimized. Above this level, the negative relationship becomes more dominant and significant. Hence, the threshold effect of inflation on investment is found at $10 \%$ where inflation decreased investment by around $2 \%$. The error of the model is found to be normally distributed and stationary. CUSUM test for model stability of the estimated model is run and the results are given in Figure (1). The test confirms the stability of the model as the cumulative sum of the recursive residuals lies inside the area between the $5 \%$ critical lines.

\section{Conclusions}

The paper detects the threshold level in the relationship between inflation and investment in Jordan over the yearly span from 1980 to 2016. The threshold level of inflation using the conditional least square is found at $10 \%$. Under this level, inflation has insignificant effect on investment. So, the monetary authority in Jordan is advised to keep inflation rates at any level below the threshold of $10 \%$.

Table 3. Results of Threshold Model by Least Square

\begin{tabular}{|c|c|c|c|c|c|}
\hline Variable & Coefficient & Std. Error & Prob. & & \\
\hline \multicolumn{6}{|c|}{$\pi^{*}=1$} \\
\hline$\alpha_{0}$ & 22.53 & 2.44 & 0.00 & R-squared & 0.236 \\
\hline$\alpha_{1}$ & 0.74 & 2.34 & 0.75 & RSS & 1222.20 \\
\hline$\alpha_{2}$ & 3.50 & 1.49 & 0.02 & & \\
\hline \multicolumn{6}{|c|}{$\pi^{*}=2$} \\
\hline$\alpha_{0}$ & 24.8581 & 1.776964 & 0 & R-squared & 0.227 \\
\hline$\alpha_{1}$ & 2.427318 & 2.091035 & 0.2536 & RSS & 1237.5 \\
\hline$\alpha_{2}$ & 3.527166 & 1.705138 & 0.046 & & \\
\hline \multicolumn{6}{|c|}{$\pi^{*}=\mathbf{3}$} \\
\hline$\alpha$ & & & & & 0.221 \\
\hline$\alpha_{1}$ & 3.859211 & 1.996652 & 0.0614 & RSS & 1246.74 \\
\hline$\alpha_{2}$ & 2.991219 & 1.966463 & 0.1372 & & \\
\hline \multicolumn{6}{|c|}{$\pi^{*}=4$} \\
\hline$\alpha_{0}$ & 27.97872 & 1.457667 & 0 & $\mathrm{R}$-squared & 0.225 \\
\hline$\alpha_{1}$ & 4.925208 & 1.984177 & 0.018 & RSS & 1240.49 \\
\hline$\alpha_{2}$ & 2.066643 & 2.342244 & 0.3836 & & \\
\hline \multicolumn{6}{|c|}{$\pi^{*}=5$} \\
\hline$\alpha_{0}$ & 28.99782 & 1.534921 & 0 & R-squared & 0.223 \\
\hline$\alpha_{1}$ & 5.398634 & 1.996375 & 0.0105 & RSS & 1242.65 \\
\hline$\alpha_{2}$ & 1.232974 & 2.820084 & 0.6646 & & \\
\hline \multicolumn{6}{|c|}{$\pi^{*}=6$} \\
\hline$\alpha_{0}$ & 30.11427 & 1.659616 & 0 & R-squared & 0.229 \\
\hline$\alpha_{1}$ & 5.9529 & 2.006007 & 0.0054 & RSS & 1233.37 \\
\hline
\end{tabular}




\begin{tabular}{|c|c|c|c|c|c|}
\hline$\alpha_{2}$ & -0.37438 & 3.381954 & 0.9125 & & \\
\hline \multicolumn{6}{|c|}{$\pi^{*}=7$} \\
\hline$\alpha_{0}$ & 31.06329 & 2.045538 & 0 & R-squared & 0.24 \\
\hline$\alpha_{1}$ & 6.309081 & 1.88866 & 0.002 & RSS & 1218.00 \\
\hline$\alpha_{2}$ & -2.38054 & 3.144927 & 0.4541 & & \\
\hline \multicolumn{6}{|c|}{$\pi^{*}=8$} \\
\hline$\alpha_{0}$ & 31.83957 & 2.269274 & 0 & $\mathrm{R}$-squared & 0.24 \\
\hline$\alpha_{1}$ & 6.477476 & 1.985574 & 0.0025 & RSS & 1208.11 \\
\hline$\alpha_{2}$ & -4.56274 & 3.411649 & 0.1897 & & \\
\hline \multicolumn{6}{|c|}{$\pi^{*}=9$} \\
\hline$\alpha_{0}$ & 27.71043 & 1.269959 & 0 & $\mathrm{R}$-squared & 0.117 \\
\hline$\alpha_{1}$ & 4.213101 & 1.276438 & 0.0022 & RSS & 1412.99 \\
\hline$\alpha_{2}$ & -0.05773 & 3.719601 & 0.9877 & & \\
\hline \multicolumn{6}{|c|}{$\pi^{*}=10$} \\
\hline$\alpha_{0}$ & 32.77423 & 2.568987 & 0 & & \\
\hline$\alpha_{1}$ & 6.285736 & 2.006769 & 0.0035 & R-squared & 0.26 \\
\hline$\alpha_{2}$ & -8.48611 & 4.050358 & 0.0435 & RSS & 1240.47 \\
\hline \multicolumn{6}{|c|}{$\pi^{*}=11$} \\
\hline$\alpha_{0}$ & 32.92468 & 2.600503 & 0 & R-squared & 0.21 \\
\hline$\alpha_{1}$ & 5.999578 & 1.941954 & 0.0039 & RSS & 1258.62 \\
\hline$\alpha_{2}$ & -10.5523 & 4.264885 & 0.0183 & & \\
\hline \multicolumn{6}{|c|}{$\pi^{*}=12$} \\
\hline$\alpha_{0}$ & 30.98524 & 2.51458 & 0 & R-squared & 0.18 \\
\hline$\alpha_{1}$ & 4.571996 & 1.787901 & 0.015 & RSS & 1260.42 \\
\hline$\alpha_{2}$ & -12.1642 & 4.662674 & 0.0133 & & \\
\hline
\end{tabular}

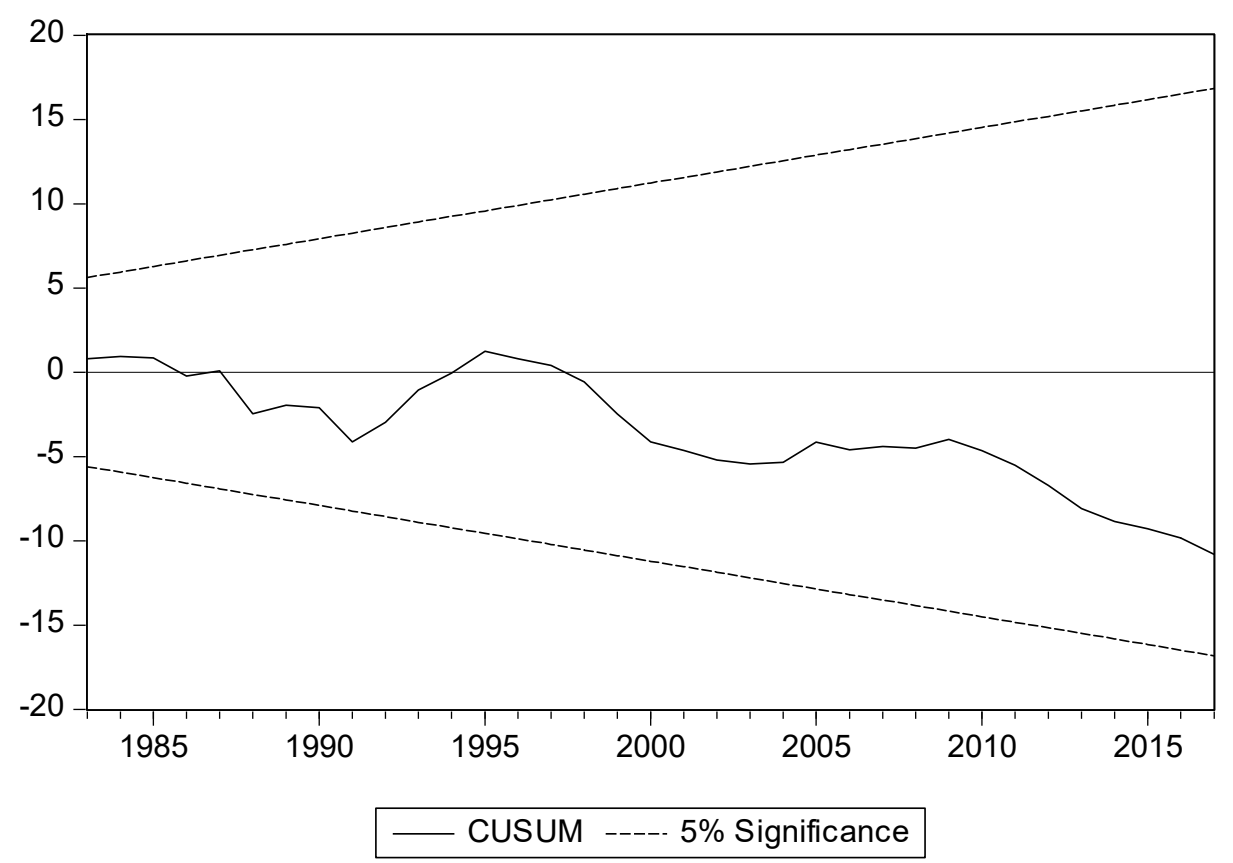

Figure 1. CUSUM Test for Model Stability 


\section{Acknowledgments}

The authors are deeply grateful to Professor Juan Carlos Cuestas for his constructive suggestions and valuable comments, which contributed to improve the quality of the manuscript.

\section{References}

Abaidoo, R. (2015). Inflation, Inflation Expectations and Investment Performance Volatility: Evaluating Potential Causal Interactions. International Journal of Economics and Finance, 7(5), 50-60.

Abel, A. B. (1983). Optimal investment under uncertainty. The American Economic Review, 73(1), 228-233.

Abel, A. B. (1990). Consumption and investment. Handbook of Monetary economics, 2, 725-778. https://doi.org/10.1016/S1573-4498(05)80021-9.

Baldwin, C. Y., \& Ruback, R. S. (1986). Inflation, uncertainty, and investment. The Journal of Finance, 41(3), 657-668. https://doi.org/10.1111/j.1540-6261.1986.tb04528.x

Ball, L. (1992). Why does high inflation raise inflation uncertainty? Journal of Monetary Economics 29(3), 371388. https://doi.org/10.1016/0304-3932(92)90032-W

Baum, C. F., Caglayan, M., \& Ozkan, N. (2004). The second moments matter: The response of bank lending behaviour to macroeconomic uncertainty, working paper 04/13, University of Leicester.

Carruth, A., Dickerson, A., \& Henley, A. (2000). What do we know about investment under uncertainty?. Journal of Economic Surveys, 14(2), 119-154. https://doi.org/10.1111/1467-6419.00107

Chen, A. H., \& Boness, A. J. (1975). Effects of uncertain inflation on the investment and financing decisions of a firm. The Journal of finance, 30(2), 469-483. https://doi.org/10.1111/j.1540-6261.1975.tb01823.x

Cizkowicz, P., \& Rzonca, A. (2013). Does inflation harm corporate investment? Empirical evidence from OECD countries. Economics, 7(16), 1-41. https://doi:10.5018/economics-ejournal.ja.2013-16

Fischer, G. (2013). Investment choice and inflation uncertainty, working paper, The London School of Economics and Political Science.

Friedman, M. (1968). The role of monetary policy. The American Economic Review, 58(1), 1-17. https://doi.org/10.1007/978-1-349-24002-9_11

Friedman, M. (1977). Nobel lecture: inflation and unemployment. Journal of political economy, 85(3), 451-472. https://doi.org/10.1086/260579

Hartman, R. (1972). The effects of price and cost uncertainty on investment. Journal of Economic Theory, 5(2), 258-266. https://doi.org/10.1016/0022-0531(72)90105-6

Iqbal, N., \& Nawaz, S. (2009). Investment, inflation and economic growth nexus. The Pakistan Development Review, 48(4), 863-874.

Khan, M. S., \& Ssnhadji, A. S. (2001). Threshold effects in the relationship between inflation and growth, IMF Staff papers 48(1), 1-21. https://doi.org/10.2307/4621658

Madsen, J. B. (2003). Inflation and investment. Scottish Journal of Political Economy, 50(4), 375-397. https://doi.org/10.1111/1467-9485.5004002

Nevile, J. W. (1975). Inflation, Company Profits and Investment. Australian Economic Review, 8(4), 35-36. https://doi.org/10.1111/j.1467-8462.1975.tb00046.x

Osakwe, L. O. (1982). The impact of Inflation on the Growth of the Nigerian Economy: Statistical Evidence. Inflation in Nigeria. Ibadan: NISER, 213-236.

Phelps, E. S. (1968). Money-wage dynamics and labor-market equilibrium. The Journal of Political Economy, 79(4), 678-711. https://doi.org/10.1086/259438

Zeira, J. (1990). Cost uncertainty and the rate of investment. Journal of Economic Dynamics and Control, 14(1), 53-63. https://doi.org/10.1016/0165-1889(90)90005-2

\section{Copyrights}

Copyright for this article is retained by the author(s), with first publication rights granted to the journal.

This is an open-access article distributed under the terms and conditions of the Creative Commons Attribution license (http://creativecommons.org/licenses/by/4.0/). 